\title{
Management of hydrocephalus in infants with severe hemophilia A: report of 2 cases
}

\author{
Stephen M. Bergin, PhD,,$^{1,2}$ Amy L. Dunn, MD, ${ }^{3}$ Luke G. F. Smith, MD, ${ }^{1}$ and \\ Annie I. Drapeau, MD, MSc ${ }^{1,4}$

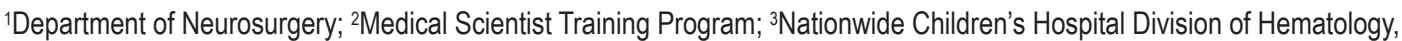 \\ Oncology \& BMT; and ${ }^{N}$ Nationwide Children's Hospital Division of Pediatric Neurosurgery, The Ohio State University College of \\ Medicine, Columbus, Ohio
}

\begin{abstract}
The authors report on the clinical course of two infants with severe hemophilia $\mathrm{A}(\mathrm{HA})$ and concomitant progressive hydrocephalus that required management with a ventriculoperitoneal shunt. The first child, with known HA, presented with a spontaneous intracranial hemorrhage and acquired hydrocephalus. He underwent cerebrospinal fluid diversion with a temporary external ventricular drain, followed by placement of a ventriculoperitoneal shunt. The second child had hydrocephalus secondary to a Dandy-Walker malformation and was diagnosed with severe HA during preoperative evaluation. He underwent placement of a ventriculoperitoneal shunt after progression of the hydrocephalus. The authors also review the treatment of hydrocephalus in patients with $\mathrm{HA}$ and describe the perioperative protocols used in their two cases. Treatment of hydrocephalus in infants with HA requires unique perioperative management to avoid complications.
\end{abstract} https://thejns.org/doi/abs/10.3171/2018.8.PEDS18409

KEYWORDS hemophilia; hydrocephalus; ventriculoperitoneal shunt; Dandy-Walker; intracranial hemorrhage

$\mathrm{P}$ EDIATRIC hydrocephalus is a surgically correctable condition, but infants with primary coagulopathies require unique management. Hemophilia A (HA) is a disorder caused by a deficiency of factor VIII (FVIII), and severe HA is defined by plasma FVIII activity less than $1 \% .{ }^{6}$ Children with $\mathrm{HA}$ are at an increased risk for intracranial hemorrhage (ICH). ${ }^{26}$ If intraventricular hemorrhage occurs, it can lead to hydrocephalus..$^{9,21,23}$

\section{Case Reports}

\section{Case 1}

Presentation

A boy was born at term via cesarean section given concerns about macrocephaly. His family history was positive for HA, and neonatal testing confirmed a diagnosis of severe HA. Subsequent mutation analysis revealed an intron 22 inversion. He was treated on demand with an extended half-life (EHL) recombinant FVIII (rFVIII) product. He received his first dose of rFVIII at 8 weeks of life as part of a study protocol.

At 14 weeks, he experienced 4 days of vomiting and increased irritability. He presented to the emergency department, where he experienced a seizure characterized by left eye deviation. He received $50 \mathrm{IU} / \mathrm{kg}$ standard half- life (SHL) rFVIII and then underwent head CT, which demonstrated a $4-\mathrm{cm}$ hematoma involving the left lateral ventricle with heterogeneous attenuation. He was placed on a continuous infusion of SHL rFVIII targeted to levels of $80 \%-120 \%$ and was admitted to the pediatric intensive care unit.

An MRI study again demonstrated the hematoma and showed moderate supratentorial ventricular enlargement and an incidental suprasellar cyst (Fig. 1). An MRA was negative for a secondary cause of bleeding.

\section{Inpatient Course}

The rFVIII infusion was adjusted with daily labs to maintain a level of $80 \%-120 \%$. He also received 14 days of oral prednisolone (including a scheduled wean) in an attempt to prevent anti-FVIII inhibitor formation. Serial imaging showed no increase in ventricle size and a persistent left lateral ventricle blood clot. He had intermittent seizures treated with levetiracetam. On admission day 7, an external ventricular drain (EVD) was placed due to increasing ventriculomegaly and signs of increased intracranial pressure (ICP) including a bulging anterior fontanelle on examination. After 10 days of cerebrospinal fluid drainage, the EVD was clamped; however, the patient continued to have dilated ventricles (on serial head ultrasonography

ABBREVIATIONS DWM = Dandy-Walker malformation; EHL = extended half-life; EVD = external ventricular drain; FVIII = factor VIII; HA = hemophilia A; ICH = intracranial hemorrhage; ICP = intracranial pressure; rFVIII = recombinant FVIII; SDH = subdural hematoma; SHL = standard half-life; VP = ventriculoperitoneal.

SUBMITTED June 28, 2018. ACCEPTED August 29, 2018.

INCLUDE WHEN CITING Published online November 2, 2018; DOI: 10.3171/2018.8.PEDS18409. 

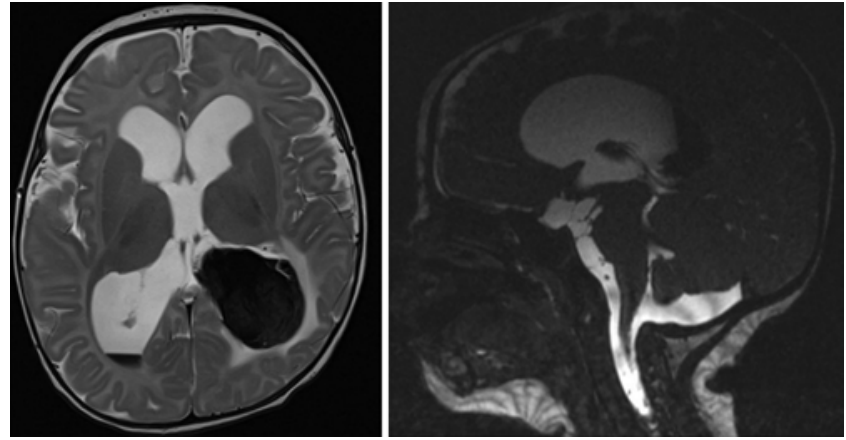

FIG. 1. Axial T2-weighted (left) and sagittal FIESTA (right) MR images obtained at presentation, showing intraventricular hemorrhage, moderate ventricular enlargement, and an incidental suprasellar cyst.

studies) and signs of elevated ICP (new-onset bradycardia), so ventriculoperitoneal (VP) shunt placement was recommended.

Prior to surgery, he received stress-dose steroids. His FVIII levels were monitored daily throughout the perioperative period, and the continuous infusion was adjusted to levels of $100 \%-120 \%$. The VP shunt was placed in the right lateral ventricle via a frontal approach. There was minimal blood loss and no complications.

On postoperative day zero, ultrasonography showed decompressed ventricles without signs of hemorrhage. Uninterrupted rFVIII infusion continued for 7 days with a maintenance target FVIII level of $80 \%-100 \%$. On postoperative day 7, the patient was transitioned to bolus SHL rFVIII infusions to achieve FVIII troughs $\geq 50 \%$ for 7 additional days. Bolus dosing was continued for 4 more weeks with a targeted trough of $\geq 25 \%$. He had no additional bleeding during this interval. At 6 weeks postoperatively, he was transitioned to once daily dosing with a targeted trough of $>1 \%$. His trough was $<1 \%$ despite daily dosing with an SHL product, so he was transitioned to EHL rFVIII and successfully maintained troughs on daily dosing.

At the 6-month postoperative evaluation, he was following developmental milestones, displaying good visual tracking, and had no neurological deficit. Imaging showed decompression of the ventricles and a new Chiari malformation type 1 (Fig. 2). The latter was most likely a re-
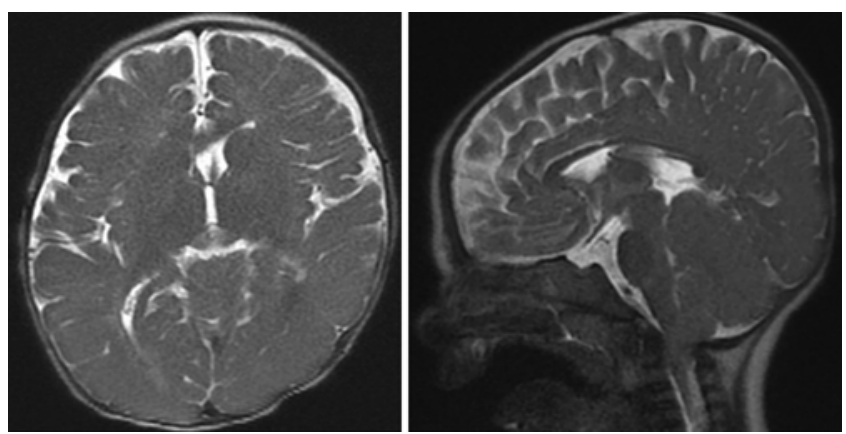

FIG. 2. Limited T2-weighted MR images obtained at 6 months postoperatively, showing an incidentally found Chiari malformation type 1 with cerebellar tonsillar descent to $9.8 \mathrm{~mm}$ below the foramen magnum.

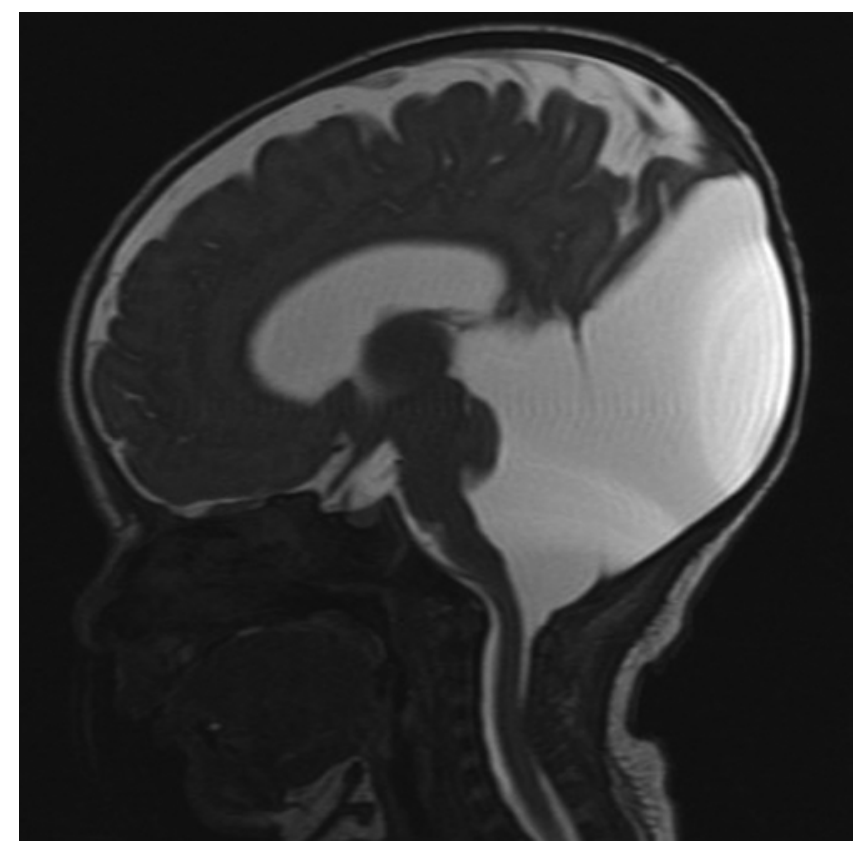

FIG. 3. Preoperative sagittal T2-weighted MR image showing hypoplasia of the cerebellar hemispheres and vermis, a retrocerebellar cyst communicating with the fourth ventricle, and an enlarged posterior fossa. Also observed were hypoplasia of the brainstem and mild ventriculomegaly of the lateral and third ventricles.

flection of his increased ICP during the attempted EVD clamp trial. He had no evidence of inhibitors and was subsequently transitioned to dosing every 36 hours to maintain trough levels $>1 \%$.

\section{Case 2}

\section{Presentation}

An abnormal prenatal ultrasonography study at 28 weeks led to the diagnosis of Dandy-Walker malformation (DWM) in this infant. Labor was induced at 37 weeks for failure to thrive, and the infant was delivered via cesarean section for failure to progress. At birth, the boy's head circumference was at the 30th percentile. Neonatal MRI showed structural anomalies consistent with a DWM and mild ventriculomegaly (Fig. 3).

He was developmentally normal at 2 months. Genetic workup was positive for 16p13.11 microduplication.

At 14 weeks of life, he displayed right-sided preference with torticollis. His head circumference had increased to the 99th percentile, and imaging demonstrated an increase in the volume of the lateral and third ventricles and split cranial suture lines. Neurosurgery was consulted, and the clinical evaluation was negative for signs or symptoms of increased ICP. Due to the significant increase in ventricle size and the crossing of two curves on his head circumference growth chart, a VP shunt was recommended.

One day after a laboratory blood draw, the patient presented to the emergency department with arm swelling in the antecubital fossa. Laboratory studies demonstrated an elevated activated partial thromboplastin time, and a diagnosis of severe HA was confirmed with FVIII $<1 \%$. His family history was negative for HA. Surgery was post- 
TABLE 1. Perioperative rFVIII management for VP shunt in infants with HA

\begin{tabular}{|c|c|c|}
\hline Course & Case $1, \mathrm{ICH}$ & Case 2, DWM \\
\hline Initial treatment & $\begin{array}{l}\text { ICH: } 50 \text { IU/kg SHL bolus, followed by } \mathrm{Cl} \text { to target } \\
80 \%-120 \% \text {; levels checked every } 12 \mathrm{hrs}\end{array}$ & $\begin{array}{l}\text { Arm hematoma: } 50-\mathrm{IU} / \mathrm{kg} \text { EHL bolus; followed by } 50 \text {-IU/kg } \\
\text { every } 12 \mathrm{hrs} \text { for } 48 \mathrm{hrs} \text {; then } 50 \text {-IU/kg every } 24 \text { hrs for } 48 \\
\text { hrs; \& then } 50-\mathrm{IU} / \mathrm{kg} \text { every } 48 \mathrm{hrs} \text { for } 72 \mathrm{hrs}\end{array}$ \\
\hline Inpatient maintenance & Oral prednisolone for 14 days; $\mathrm{Cl}$ target $80 \%-120 \%$ & Prophylactic: bolus of $50 \mathrm{IU} / \mathrm{kg}$ twice weekly \\
\hline Preop & Bolus $50 \mathrm{IU} / \mathrm{kg} ; \mathrm{Cl}$ at $5 \mathrm{IU} / \mathrm{kg} / \mathrm{hr}$, target $100 \%-120 \%$ & Bolus of $50 \mathrm{IU} / \mathrm{kg} ; \mathrm{Cl}$ at $5 \mathrm{IU} / \mathrm{kg} / \mathrm{hr}$, target $80 \%-120 \%$ \\
\hline Intraop & $\mathrm{Cl}$ target $80 \%-120 \%$ & $\mathrm{Cl}$ target $80 \%-120 \%$ \\
\hline Postop & $\begin{array}{l}\text { POD 0-7: } \mathrm{Cl} \text { w/ target } 80 \%-100 \% \text {; POD } 7-14 \text { : bolus } \\
\text { infusion every } 12 \mathrm{hrs} \text {, trough target } \geq 50 \% \text {; POD } 15-42 \text { : } \\
\text { bolus infusion every } 24 \mathrm{hrs}\end{array}$ & $\begin{array}{l}\text { POD 0-4: Cl for } 4 \text { days, target } 80 \%-120 \% \text {; POD } 5-14 \text { : bolus } \\
\text { infusion every } 12 \mathrm{hrs,} \mathrm{trough} \mathrm{target} \geq 50 \% \text {; POD } 15-42 \text { : } \\
\text { bolus infusion every } 24-48 \mathrm{hrs} \text {, trough target }>25 \%\end{array}$ \\
\hline Discharge & POD 8 & POD 5 \\
\hline
\end{tabular}

$\mathrm{Cl}=$ continuous infusion $; \mathrm{POD}=$ postoperative day.

poned for management of the arm hematoma given concerns about impending compartment syndrome. Treatment was initiated with an EHL rFVIII concentrate. The hemorrhage resolved after an initial 50-IU/kg bolus, followed by a $50-\mathrm{IU} / \mathrm{kg}$ bolus every 12 hours for 48 hours, then every day for 48 hours, and then every other day for 72 hours. Upon resolution of the hematoma, the patient was transitioned to a prophylactic regimen of $50 \mathrm{IU} / \mathrm{kg}$ twice weekly. No anti-FVIII inhibitors developed during these initial exposures to rFVIII. After 9 exposure days to rFVIII, the boy was reassessed in the neurosurgery clinic, and because of an increased head circumference and increasing lethargy, the hemophilia and neurosurgery teams collaborated on a management plan for VP shunt placement (Table 1).

\section{Inpatient Course}

On the morning of surgery, he received a bolus of 50 $\mathrm{IU} / \mathrm{kg} \mathrm{rFVIII} \mathrm{and} \mathrm{a} \mathrm{continuous} \mathrm{infusion} \mathrm{was} \mathrm{initiated} \mathrm{at} 5$ $\mathrm{IU} / \mathrm{kg} / \mathrm{hr}$. Levels were obtained to maintain a goal of $80 \%-$ $120 \%$. A VP shunt was placed in the right lateral ventricle via a right frontal approach. There was minimal blood loss and no complications.

Postoperatively, he continued to receive the continuous infusion of rFVIII for 4 days with a target of $80 \%-120 \%$. Head CT confirmed placement of the VP shunt but also demonstrated small bilateral subdural hematomas (SDHs; Fig. 4), without midline shift or mass effect. Hemoglobin and hematocrit levels were stable. Follow-up ultrasound studies revealed resolution of these hematomas prior to discharge on postoperative day 5 . The boy was weaned to dosing every 12 hours with FVIII troughs $\geq 50 \%$ through postoperative day 14 . He was then transitioned to daily dosing to keep troughs $>25 \%$ to complete 6 weeks of therapy. At 2 months' follow-up, he was doing well and attaining expected developmental milestones. No FVIII inhibitors developed.

\section{Discussion}

Management of hydrocephalus in infants with severe HA requires unique considerations by the neurosurgeon and hematologist. These case reports offer examples of two different perioperative management scenarios and illustrate the importance of multidisciplinary collaboration.

\section{Hematological Management}

A feared complication of HA treatment is the development of anti-FVIII inhibitors, which occur in 22\%-30\% of patients and can render FVIII treatment ineffective. ${ }^{14,18}$ Known risk factors for anti-FVIII inhibitor development include the type of FVIII mutation, patient race, and family history. Potential risk factors include FVIII therapy in the setting of infection, inflammation, or surgery; type of rFVIII concentrate; and intensity of rFVIII treatment. ${ }^{14}$

Primary prophylaxis with FVIII replacement reduces the risk of ICH and is recommended early in life. ${ }^{2}$ Previously untreated patients are at increased risk of developing anti-FVIII inhibitors, but low-dose primary prophylactic rFVIII decreases this risk. ${ }^{3,14}$ The patient in case 1 required immediate high-dose rFVIII to treat an acute bleed; therefore, the hematology team recommended a trial of immune suppression with steroids for the theoretical benefit of reducing inflammation and preventing inhibitor development. Anticipation of a nonemergent VP shunt surgery provided time for perioperative care of the coagulopathy. Surgery was delayed for the DWM patient, so the initiation of low-dose rFVIII was possible. The World Federation of Hemophilia provides separate recommendations for the management of FVIII levels in an acute hemorrhage and for surgery. ${ }^{31}$ In both of our cases, the recommendations were adapted to the scenario (Table 1) and were influenced by close communication between the surgeon and the hematologist. Also, the use of an EHL product in case 2 allowed for earlier transition to bolus dosing.
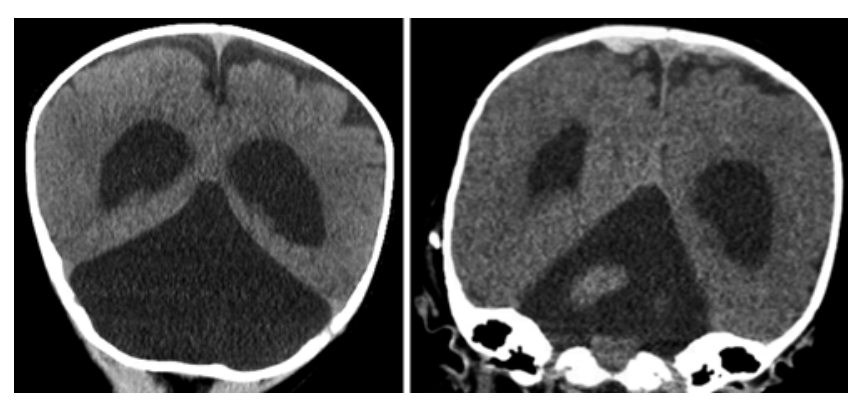

FIG. 4. Coronal CT scans obtained preoperatively (left) and on postoperative day 1 (right). Note the bilateral subdural bleeds of 5 and $4 \mathrm{~mm}$ at the vertex. 


\section{Neurosurgical Management}

Intracranial hematomas can occur as a complication of shunt procedures, and most bleeds are SDHs, ${ }^{15,24}$ which can range in size. Therapeutic options include evacuation of the SDH, but asymptomatic bleeds are often conservatively monitored on serial imaging. ${ }^{1}$ Despite adequate rFVIII levels, our patient with DWM developed small, bilateral SDHs after VP shunting, which were followed with ultrasound studies to resolution. Preventing an interruption to the rFVIII infusion was paramount for avoiding excess bleeding, and care teams were instructed to avoid any line obstructions. Nonsteroidal anti-inflammatory drugs and intramuscular medicines were avoided. Factor VIII assays were sent immediately postoperatively and were obtained daily.

Intracranial hemorrhages in the pediatric HA population are often spontaneous ${ }^{9}$ and more frequent in the first 2 years of life..$^{5,19}$ Management of ICH requires early recognition and immediate FVIII replacement. For a presumed ICH, FVIII levels should be immediately raised to initial levels of $80 \%-100 \%$ for 1-7 days, followed by troughs of $50 \%$ for 8-14 days. ${ }^{31}$ Surgical intervention is performed in $33 \%-39 \%$ of cases. ${ }^{9,32,39}$ In one retrospective study of 66 children with a primary coagulopathy and ICH, 22 underwent surgery, which consisted of craniotomy and evacuation in 16 cases and insertion of a VP shunt or drain in 6 cases. ${ }^{9}$ However, these studies did not describe the management of FVIII levels for children who develop hydrocephalus and require surgery. Our report offers specific examples of perioperative FVIII management leading to successful surgery.

Reports of hydrocephalus in patients with HA, as seen in our patients, are scarce. ${ }^{9,29,37}$ A VP shunt is indicated if temporizing measures fail to control the ICP and if hydrocephalus persists. ${ }^{13}$ In certain cases, an alternative to shunt placement is endoscopic third ventriculostomy with or without choroid plexus cauterization, which has been reported in the treatment of DWM-associated hydrocephalus. ${ }^{34,35}$ The benefit of this procedure is to avoid future surgery related to shunt hardware infection or malfunction. The surgeon must weigh the potential benefits against the potential complications, which include uncontrolled bleeding, injury to vascular structures, and a variable failure rate based on different factors. ${ }^{7}$ Endoscopic third ventriculostomy has been reported in HA patients but has failed and required a shunt or its outcome was unknown. ${ }^{8,20}$ With the appropriate protocol (Table 1), VP shunting can be performed with minimal blood loss.

Dandy-Walker malformation accounts for approximately $1 \%$ of developmental obstructive hydrocephalus in infants, ${ }^{27}$ and obstructive hydrocephalus in the setting of hemophilia is also rare. A literature review revealed two cases of obstructive hydrocephalus in adults with HA attributed to arachnoid cysts; one cyst was located in the middle fossa and required shunting ${ }^{13}$ and the other was located in the suprasellar region. ${ }^{22}$ Other cases of cysts in HA have been reported but either the patients did not develop hydrocephalus or the cyst was considered an incidental finding. 4

The unusual concomitant finding of HA and DWM warrants a brief discussion. The F8C gene responsible for HA is cytogenetically located at $\mathrm{Xq} 28$. Also located at $\mathrm{Xq} 28$ is the gene $L C A M 1,{ }^{11}$ which is implicated in the most common genetic cause of congenital hydrocephalus, the X-linked L1 syndrome. ${ }^{33,36}$ L1 syndrome also includes central nervous system malformations that are similar to DWM, such as cerebellar hypoplasia, small brainstem, and hypogenesis of the medullary pyramids. ${ }^{16,36}$ Our case provides a clinical example of an association between HA and DWM. Multiple case series have reported a male predominance in DWM (ratio 1.4-2.0), ${ }^{25,30,35}$ which may suggest an $\mathrm{X}$-linked process. ${ }^{10,38}$ Mutations in X-located genes, such as LCAM1 and $O P H N 1$, can cause cerebellar dysgenesis and DWM. ${ }^{17,28}$ The mutation status of such X-linked genes in our patient is unknown.

\section{Conclusions}

In summary, our cases demonstrate that with a multidisciplinary approach, our treatment of hydrocephalus with a VP shunt was safe in the management of infants with HA. Although each case requires individualization based on severity of hemophilia and type of FVIII concentrate utilized, our treatment examples may provide value to other neurosurgeons and hematologists facing similar problems.

\section{References}

1. Aguiar PH, Shu EB, Freitas AB, Leme RJ, Miura FK, Marino $\mathrm{R}$ Jr: Causes and treatment of intracranial haemorrhage complicating shunting for paediatric hydrocephalus. Childs Nerv Syst 16:218-221, 2000

2. Andersson NG, Auerswald G, Barnes C, Carcao M, Dunn AL, Fijnvandraat K, et al: Intracranial haemorrhage in children and adolescents with severe haemophilia A or B-the impact of prophylactic treatment. Br J Haematol 179:298307, 2017

3. Auerswald G, Bidlingmaier C, Kurnik K: Early prophylaxis/ FVIII tolerization regimen that avoids immunological danger signals is still effective in minimizing FVIII inhibitor developments in previously untreated patients-long-term followup and continuing experience. Haemophilia 18:e18-e20, 2012

4. Balak N, Silav G, Kiliç Y, Timur C, Elmaci I: Successful surgical treatment of a hemophiliac infant with nontraumatic acute subdural hematoma. Surg Neurol 68:537-540, 2007

5. Bladen M, Main E, Khair K, Hubert N, Koutoumanou E, Liesner R: The incidence, risk and functional outcomes of intracranial haemorrhage in children with inherited bleeding disorders at one haemophilia center. Haemophilia 22:556563,2016

6. Blanchette VS, Key NS, Ljung LR, Manco-Johnson MJ, van den Berg HM, Srivastava A: Definitions in hemophilia: communication from the SSC of the ISTH. J Thromb Haemost 12:1935-1939, 2014

7. Bouras T, Sgouros S: Complications of endoscopic third ventriculostomy. World Neurosurg 79 (2 Suppl):22.e9-22.e12, 2013

8. Buchbinder D, Steward CG, Puthenveetil G, Nugent D, Hsieh L, Kirov I, et al: Successful cord blood transplantation in a patient with malignant infantile osteopetrosis and hemophilia. Pediatr Transplant 17:E20-E24, 2013

9. Chalmers EA, Alamelu J, Collins PW, Mathias M, Payne J, Richards M, et al: Intracranial haemorrhage in children with inherited bleeding disorders in the UK 2003-2015: a national cohort study. Haemophilia 24:641-647, 2018

10. Cowles T, Furman P, Wilkins I: Prenatal diagnosis of Dandy- 
Walker malformation in a family displaying X-linked inheritance. Prenat Diagn 13:87-91, 1993

11. Ferese R, Zampatti S, Griguoli AM, Fornai F, Giardina E, Barrano G, et al: A new splicing mutation in the L1CAM gene responsible for X-linked hydrocephalus (HSAS). J Mol Neurosci 59:376-381, 2016

12. Fewel ME, Levy ML, McComb JG: Surgical treatment of 95 children with 102 intracranial arachnoid cysts. Pediatr Neurosurg 25:165-173, 1996

13. Flannery AM, Duhaime AC, Tamber MS, Kemp J: Pediatric hydrocephalus: systematic literature review and evidencebased guidelines. Part 3: Endoscopic computer-assisted electromagnetic navigation and ultrasonography as technical adjuvants for shunt placement. J Neurosurg Pediatr 14 (Suppl 1):24-29, 2014

14. Gouw SC, van den Berg HM, Fischer K, Auerswald G, Carcao M, Chalmers E, et al: Intensity of factor VIII treatment and inhibitor development in children with severe hemophilia A: the RODIN study. Blood 121:4046-4055, 2013

15. Hoppe-Hirsch E, Sainte Rose C, Renier D, Hirsch JF: Pericerebral collections after shunting. Childs Nerv Syst 3:97-102, 1987

16. Jouet M, Rosenthal A, Armstrong G, MacFarlane J, Stevenson R, Paterson J, et al: X-linked spastic paraplegia (SPG1), MASA syndrome and X-linked hydrocephalus result from mutations in the L1 gene. Nat Genet 7:402-407, 1994

17. Kanemura Y, Okamoto N, Sakamoto H, Shofuda T, Kamiguchi H, Yamasaki M: Molecular mechanisms and neuroimaging criteria for severe L1 syndrome with X-linked hydrocephalus. J Neurosurg 105 (5 Suppl):403-412, 2006

18. Kulkarni R, Presley RJ, Lusher JM, Shapiro AD, Gill JC, Manco-Johnson M, et al: Complications of haemophilia in babies (first two years of life): a report from the Centers for Disease Control and Prevention Universal Data Collection System. Haemophilia 23:207-214, 2017

19. Ljung R, Lindgren AC, Petrini P, Tengborn L: Normal vaginal delivery is to be recommended for haemophilia carrier gravidae. Acta Paediatr 83:609-611, 1994

20. Mahlangu JN, Ragni M, Gupta N, Rangarajan S, Klamroth $\mathrm{R}$, Oldenburg J, et al: Long-acting recombinant factor VIII $\mathrm{Fc}$ fusion protein $(\mathrm{rFVIIIFc})$ for perioperative haemostatic management in severe haemophilia A. Thromb Haemost 116:1-8, 2016

21. Matsuda M, Handa J, Asato R, Handa H, Yasunaga K: Surgical treatment of intracranial hematoma and hydrocephalus in an infant with hemophilia A. Surg Neurol 7:199-203, 1977

22. Mbekeani JN, Ahmed M: An incidental large arachnoid cyst associated with compensated hydrocephalus in a patient with hemophilia A. Int J Pediatr and Adol Med 2:166-167, 2015

23. McCarthy JW, Coble LL: Intracranial hemorrhage and subsequent communicating hydrocephalus in a neonate with classical hemophilia. Pediatrics 51:122-124, 1973

24. Merkler AE, Ch'ang J, Parker WE, Murthy SB, Kamel H: The rate of complications after ventriculoperitoneal shunt surgery. World Neurosurg 98:654-658, 2017

25. Mohanty A, Biswas A, Satish S, Praharaj SS, Sastry KV: Treatment options for Dandy-Walker malformation. J Neurosurg 105 (5 Suppl):348-356, 2006

26. Nelson MD Jr, Maeder MA, Usner D, Mitchell WG, Fenstermacher MJ, Wilson DA, et al: Prevalence and incidence of intracranial haemorrhage in a population of children with haemophilia. The Hemophilia Growth and Development Study. Haemophilia 5:306-312, 1999

27. Osenbach RK, Menezes AH: Diagnosis and management of the Dandy-Walker malformation: 30 years of experience. Pediatr Neurosurg 18:179-189, 1992

28. Philip N, Chabrol B, Lossi AM, Cardoso C, Guerrini R, Dobyns WB, et al: Mutations in the oligophrenin-1 gene
(OPHN1) cause X linked congenital cerebellar hypoplasia. J Med Genet 40:441-446, 2003

29. Sadek SA, Bin-Nakhi HA, Al-Naqeeb N, Kumar R: Intracranial hemorrhage in a newborn with hemophilia. Ann Saudi Med 20:433-435, 2000

30. Sasaki-Adams D, Elbabaa SK, Jewells V, Carter L, Campbell JW, Ritter AM: The Dandy-Walker variant: a case series of 24 pediatric patients and evaluation of associated anomalies, incidence of hydrocephalus, and developmental outcomes. J Neurosurg Pediatr 2:194-199, 2008

31. Srivastava A, Brewer AK, Mauser-Bunschoten EP, Key NS, Kitchen S, Llinas A, et al: Guidelines for the management of hemophilia. Haemophilia 19:e1-e47, 2013

32. Stieltjes N, Calvez T, Demiguel V, Torchet MF, Briquel ME, Fressinaud E, et al: Intracranial haemorrhages in French haemophilia patients (1991-2001): clinical presentation, management and prognosis factors for death. Haemophilia 11:452-458, 2005

33. Vos YJ, de Walle HE, Bos KK, Stegeman JA, Ten Berge AM, Bruining M, et al: Genotype-phenotype correlations in L1 syndrome: a guide for genetic counselling and mutation analysis. J Med Genet 47:169-175, 2010

34. Warf BC, Campbell JW, Riddle E: Initial experience with combined endoscopic third ventriculostomy and choroid plexus cauterization for post-hemorrhagic hydrocephalus of prematurity: the importance of prepontine cistern status and the predictive value of FIESTA MRI imaging. Childs Nerv Syst 27:1063-1071, 2011

35. Warf BC, Dewan M, Mugamba J: Management of DandyWalker complex-associated infant hydrocephalus by combined endoscopic third ventriculostomy and choroid plexus cauterization. J Neurosurg Pediatr 8:377-383, 2011

36. Weller S, Gärtner J: Genetic and clinical aspects of X-linked hydrocephalus (L1 disease): Mutations in the L1CAM gene. Hum Mutat 18:1-12, 2001

37. Zakaria Z, Kaliaperumal C, Crimmins D, Caird J: Neurosurgical management in children with bleeding diathesis: auditing neurological outcome. J Neurosurg Pediatr 21:38-43, 2018

38. Zanni G, Bertini ES: X-linked disorders with cerebellar dysgenesis. Orphanet J Rare Dis 6:24, 2011

39. Zanon E, Iorio A, Rocino A, Artoni A, Santoro R, Tagliaferri $A$, et al: Intracranial haemorrhage in the Italian population of haemophilia patients with and without inhibitors. Haemophilia 18:39-45, 2012

\section{Disclosures}

Dr. Dunn reports grants, personal fees, and nonfinancial support from Bayer, CSL Behring, Pfizer, Shire, and Hema Biologics; grants and personal fees from Bioverativ; personal fees and nonfinancial support from Medscape; grants from Alnylam and Octapharma; and personal fees and nonfinancial support from Novo Nordisk, during the conduct of the study; and other from Little Seed Inc.

\section{Author Contributions}

Conception and design: Drapeau, Bergin. Acquisition of data: all authors. Analysis and interpretation of data: all authors. Drafting the article: Bergin. Critically revising the article: all authors. Reviewed submitted version of manuscript: all authors. Approved the final version of the manuscript on behalf of all authors: Drapeau. Study supervision: Drapeau.

\section{Correspondence}

Annie I. Drapeau: Nationwide Children's Hospital, The Ohio State University College of Medicine, Columbus, $\mathrm{OH}$. annie. drapeau@nationwidechildrens.org. 